\title{
Pharmacokinetic Interaction between Indinavir and Darunavir with Low-Dose Ritonavir in Healthy Volunteers
}

\author{
Vanitha Sekar ${ }^{a}$ Eric Lefebvre ${ }^{a}$ Tine De Marez ${ }^{a}$ Martine De Pauw ${ }^{b}$ \\ Els De Paepe $^{\mathrm{b}}$ Tony Vangeneugden ${ }^{\mathrm{b}}$ Richard M.W. Hoetelmans ${ }^{\mathrm{b}}$

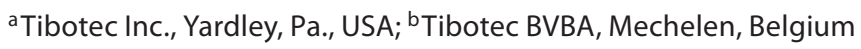

\section{Key Words}

Darunavir · Ritonavir • Indinavir · Pharmacokinetic

interactions

\begin{abstract}
Objective: To investigate the potential for a pharmacokinetic interaction between darunavir (DRV, TMC114, Prezista ${ }^{\circledR}$ ), indinavir (IDV, Crixivan ${ }^{\circledR}$ ) and low-dose ritonavir (RTV, Norvir $\left.{ }^{\circledR}\right)$. Methods: In three 7-day sessions, 17 HIV-negative healthy volunteers received treatment A (DRV/r 400/100 mg b.i.d.), treatment $B$ (IDV/r 800/100 mg b.i.d.) and treatment $C$ (DRV/r 400/100 mg b.i.d. + IDV 800 mg b.i.d.). On day 7, full pharmacokinetic profiles of DRV, IDV and RTV were determined. Safety and tolerability were also assessed. Results: Based on the least-squares means ratios, the steady-state exposure (area under the curve, $A \cup C_{12 h}$ ) and plasma concentrations $\left(C_{\min }\right.$ and $\left.C_{\text {max }}\right)$ of IDV were increased by 23,125 and $8 \%$, respectively, when DRV was co-administered. The coadministration of IDV with DRV/r resulted in increases of 24, 44 and $11 \%$ for, respectively, DRV AUC $C_{12 h}, C_{\min }$ and $C_{\text {max }}$, compared with administration of DRV/r alone. Eight volunteers discontinued due to an adverse event. Overall, adverse events and laboratory abnormalities were more commonly reported during treatments including IDV. Conclusions:
\end{abstract}

When used in combination with DRV/r, dose adjustment of IDV from $800 \mathrm{mg}$ b.i.d. to $600 \mathrm{mg}$ b.i.d. may be warranted in cases of intolerance.

Copyright $\odot 2010$ S. Karger AG, Basel

\section{Introduction}

The protease inhibitor (PI) darunavir (DRV, TMC114, Prezista ${ }^{\circledR}$ ) binds tightly to the HIV-1 protease and has a potent activity against both wild-type and resistant HIV1 strains [1-3]. DRV is co-administered with low-dose ritonavir (RTV, Norvir $\left.{ }^{\circledR} ; \mathrm{DRV} / \mathrm{r}\right)$ to improve its pharmacokinetic (PK) profile [4]. DRV/r is approved for the treatment of antiretroviral (ARV) treatment-experienced (600/100 mg b.i.d.) and treatment-naïve (800/100 mg q.d.) HIV-1 infected adult patients, in combination with other ARVs $[1,2]$.

Indinavir (IDV) is another PI also indicated for the treatment of HIV-1-infected patients in combination

Some of the data shown in this article have previously been presented at the International Symposium on HIV and Emerging Infectious Diseases, June 21-23, 2006, Toulon, France, abstract PP4.15.

\section{KARGER}

Fax +41613061234 E-Mail karger@karger.ch www.karger.com
(ㄷ) 2010 S. Karger AG, Basel

0300-5526/10/0533-0176\$26.00/0

Accessible online at:

www.karger.com/int
Vanitha Sekar

Tibotec Inc.

1020 Stony Hill Road

Yardley, PA 19067 (USA)

Tel. +1 609730 7500, Fax +1 609730 7501, E-Mail vsekar@ tibus.jnj.com 
with other ARVs, although there has been a decline in its use in clinical practice over the years. The recommended dose of IDV for adults is $800 \mathrm{mg}$ orally every $8 \mathrm{~h}$ (t.i.d.) [5]. However, IDV is often used twice daily in combination with low-dose RTV (IDV/r 800/100 mg b.i.d.) [6].

Although current treatment guidelines recommend initial combinations of two nucleoside/nucleotide reverse transcriptase inhibitors (NRTIs) and either a non-nucleoside reverse transcriptase inhibitor (NNRTI) or a PI (with or without RTV boosting) [7], and do not recommend co-administration of two PIs with low-dose RTV (often referred to as double-boosted PI therapy), DRV/r and IDV may be co-administered to maximize the number of active drugs in ARV treatment-experienced HIV1-infected patients, particularly in patients infected with HIV strains with established PI resistance, or in those with extensive nucleoside or non-nucleoside reverse transcriptase inhibitor resistance but with retained PI susceptibility [8].

The metabolism of DRV, IDV and RTV is mediated by the cytochrome P450 3A (CYP3A) isoenzyme; all three drugs are substrates as well as inhibitors of CYP3A $[1,2,5,9]$. DRV/r also induces CYP2C9 and CYP2C19 activities and inhibits CYP2D6 activity; these effects may be attributed to the co-administration of low-dose RTV and are consistent with reports on the interaction profile of RTV $[9,10]$. Since IDV, DRV and RTV use similar metabolic pathways, the potential pharmacokinetic interaction of these drugs was investigated in the present study.

\section{Methods}

\section{Study Design}

This was an open-label, randomized, 3-way crossover study to investigate the potential for a pharmacokinetic interaction between DRV/r and IDV in healthy volunteers. Eligibility criteria included: aged 18-55 years, BMI 18-30, HIV-negative status, a general medical condition unlikely to interfere with assessments and study completion, and not having participated in any investigational drug trial within 30 days prior to screening. In three 7-day sessions, subjects were randomized to receive treatment A (DRV/r 400/100 mg b.i.d. on days 1-6 and an additional morning dose on day 7), treatment B (IDV/r $800 / 100 \mathrm{mg}$ b.i.d. on days $1-6$ and an additional morning dose on day 7) and treatment $\mathrm{C}$ (DRV/r 400/100 mg b.i.d. + IDV $800 \mathrm{mg}$ b.i.d. on days 1-6 and an additional morning dose on day 7 ). Treatments were separated by a washout period of at least 7 days. The volunteers remained in the study unit from day -1 until $12 \mathrm{~h}$ after study medication intake on day 7 for all treatments. The subjects had to drink at least 1.5 liters of water during the course of $24 \mathrm{~h}$ on days 1-7 of all treatments to ensure adequate hydration (IDV therapy increases the risk of nephrolithiasis [5]). DRV was formulated as a 400-mg tablet, RTV as a 100-mg capsule and IDV as a 400-mg capsule. All study medication was taken orally within 15 min after completing a meal. DRV (treatment A) or IDV (treatment B) were taken within 5 min after administration of RTV. When DRV, RTV and IDV were co-administered (treatment $C$ ), the order of intake was first RTV, then DRV, followed by IDV (consecutive intakes were within $5 \mathrm{~min}$ ). The time of each intake of study medication and times of breakfast and dinner were recorded in the case report forms. On day 7, full pharmacokinetic profiles were determined of DRV (treatment A and C), IDV (treatment B and C) and RTV (all treatments). On day 7 of all treatments, study medication had to be taken within 15 min after completing a standard breakfast. Resumption of water and food intake was allowed 2 and $4 \mathrm{~h}$ after breakfast, respectively.

The study protocol and amendment were reviewed and approved by the appropriate Institutional Review Board and health authorities, and were conducted in accordance with the Declaration of Helsinki. Written informed consent was obtained from all volunteers.

\section{Pharmacokinetic Assessments}

Plasma samples for DRV (treatments A and C), IDV (treatments B and C) and RTV (all treatments) were taken predose in the morning on days $1,5,6$ and 7 , and $0.5,1,1.5,2,3,4,5,6,9$ and $12 \mathrm{~h}$ postdose on day 7 . Exact times of blood sampling for pharmacokinetics were recorded and plasma samples were stored until analysis $\left(\leq-18^{\circ}\right)$.

Plasma concentrations of DRV, IDV and RTV were determined by validated liquid chromatography-mass spectrometry/ mass spectrometry (LC-MS/MS) methods. The lower limit of quantification (LLOQ) was $10.0 \mathrm{ng} / \mathrm{ml}$ for DRV, $5.00 \mathrm{ng} / \mathrm{ml}$ for RTV and $20.0 \mathrm{ng} / \mathrm{ml}$ for IDV. The precision and accuracy for the $\operatorname{DRV}(30.0,400$ and 8,000 ng/ml), RTV (15.0, 200 and 4,000 ng/ $\mathrm{ml})$ and IDV (60.0, 750 and 15,000 ng/ml) quality control (QC) samples in plasma were less than 7,8 and $7 \%$, respectively, and met the predefined criteria of maximum $15 \%[11,12]$.

Safety Assessments

Safety and tolerability were assessed throughout the study by adverse events (AEs), clinical laboratory evaluations, physical examinations, vital signs and 12-lead ECGs. AEs and laboratory abnormalities were graded according to the AIDS Clinical Trials Group (ACTG) severity grading scale (grade $1=$ mild, grade $2=$ moderate, grade $3=$ severe, grade $4=$ potentially life-threatening).

\section{Statistical Methods}

Descriptive statistics were calculated for the plasma concentrations of DRV, IDV and RTV. Pharmacokinetic analysis was done using WinNonlin Professional ${ }^{\mathrm{TM}}$ (version 3.3; Pharsight Corporation, Mountain View, Calif., Calif., USA). Noncompartmental analysis model 200 (extravascular input, plasma data) was applied for the pharmacokinetic analysis. Pharmacokinetic parameters for DRV, IDV and RTV included area under the curve from time of administration to $12 \mathrm{~h}$ postdosing $\left(\mathrm{AUC}_{12 \mathrm{~h}}\right)$, predose plasma concentrations $\left(\mathrm{C}_{0 \mathrm{~h}}\right)$, minimum $\left(\mathrm{C}_{\text {min }}\right)$ and maximum $\left(\mathrm{C}_{\max }\right)$ plasma concentrations and time to reach $\mathrm{C}_{\max }\left(\mathrm{t}_{\max }\right)$. The primary pharmacokinetic parameters were $\mathrm{C}_{0 \mathrm{~h}}, \mathrm{C}_{\min }, \mathrm{C}_{\max }$ and $\mathrm{AUC}_{12 \mathrm{~h}}$ on the logarithmic scale. 


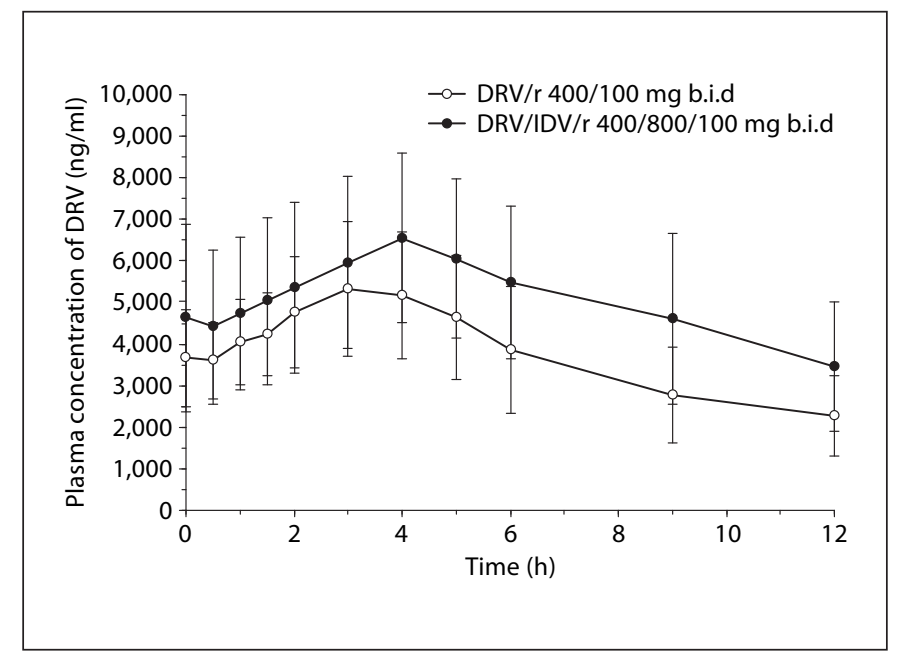

Fig. 1. Mean plasma concentration time curves of darunavir on day 7 after oral administration of DRV/r 400/100 mg b.i.d. alone (treatment A) and in combination with IDV $800 \mathrm{mg}$ b.i.d. (treatment C).

Statistical analyses were performed comparing treatments $C$ (test) versus A (reference) for DRV and RTV and comparing treatments C (test) versus B (reference) for IDV and RTV. Only paired observations for the compared treatments were included in a statistical analysis.

The least-squares (LS) means of the primary PK parameters for each treatment group were calculated using a linear mixed effects model, controlling for treatment, sequence and period as fixed effects and subject as a random effect. A $90 \%$ confidence interval was constructed around the difference between the LS means of test and reference treatment. Both the difference between the LS means and the $90 \%$ confidence limits were retransformed to the original scale. Period effects were considered significant at the $5 \%$ level and sequence effects were considered significant at the $10 \%$ level. If period and sequence effects were not significant, they were not retained in the model. $\mathrm{T}_{\max }$ was subjected to the nonparametric Koch test using the cross-over design tool of WinNonlin Professional ${ }^{\mathrm{TM}}$ [13].

Predose plasma concentrations on days 5, 6 and 7 of each treatment were compared graphically to verify the achievement of steady-state conditions for DRV, IDV and RTV.

Frequency tabulations were constructed for the incidence of AEs and laboratory abnormalities.

\section{Results}

A total of $18 \mathrm{HIV}$-negative healthy volunteers were randomized, but 17 volunteers received treatment (one volunteer no longer met the in- and exclusion criteria at baseline). Nine of these 17 volunteers completed the study.

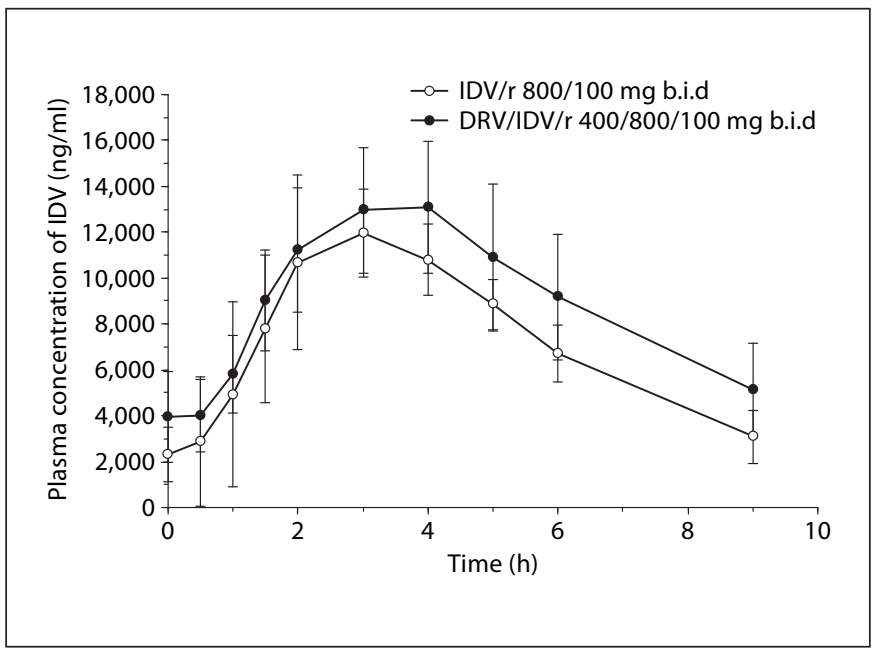

Fig. 2. Mean plasma concentration time curves of indinavir on day 7 after oral administration of IDV/r 800/100 mg b.i.d. alone (treatment B) and in combination with DRV $400 \mathrm{mg}$ b.i.d. (treatment C).

Eight volunteers discontinued study treatment during the first session due to an $\mathrm{AE}$ (refer to results for safety and tolerability below). Full pharmacokinetic profiles (on day 7) were available for 10 volunteers for treatment $A$ (DRV and RTV), 9 volunteers for treatment B (IDV and RTV) and 10 subjects for treatment C (DRV, IDV and RTV). The median age (range) was 25 (19-42) years. The majority of the volunteers were female $(76 \%)$ and the median BMI (range) was 24.7 (19-29).

\section{Pharmacokinetic Data}

The mean plasma concentration-time curves of DRV (fig. 1) were higher after co-administration of IDV (treatment C) compared with DRV/r alone (treatment A). The mean pharmacokinetic parameters (and LS means ratios) for DRV during treatment $\mathrm{A}$ and $\mathrm{C}$ are shown in table 1. Based on the LS means ratio, the mean exposure $\left(\mathrm{AUC}_{12 \mathrm{~h}}\right)$ of DRV was $24 \%$ higher when IDV was co-administered with DRV/r. The mean $\mathrm{C}_{\min }$ and $\mathrm{C}_{\max }$ of DRV were increased by 44 and $11 \%$, respectively.

The presence of DRV also increased the systemic exposure of IDV. The mean plasma concentration-time curves of IDV during administration of IDV/r alone (treatment B) and in the presence of DRV (treatment C) are shown in figure 2, and the mean pharmacokinetic parameters (and LS means ratios) for IDV during the two treatments are shown in table 2 . The LS means ratios especially showed an increase in the $C_{\min }$ of IDV in the 
Table 1. Pharmacokinetic results of darunavir on day 7 after administration of DRV/r 400/100 mg b.i.d. alone (treatment A) and in combination with IDV $800 \mathrm{mg}$ b.i.d. (treatment C)

\begin{tabular}{|c|c|c|c|}
\hline Pharmacokinetic parameter & $\begin{array}{l}\mathrm{DRV} / \mathrm{r} \text { alone } \\
\text { (treatment } \mathrm{A} \text {; reference) }\end{array}$ & $\begin{array}{l}\mathrm{DRV} / \mathrm{r}+\mathrm{IDV} \\
\text { (treatment C; test) }\end{array}$ & $\begin{array}{l}\text { LS means ratio test/ } \\
\text { reference }(90 \% \mathrm{CI})\end{array}$ \\
\hline $\mathrm{n}$ & $11^{*}$ & 10 & 9 \\
\hline Mean $\mathrm{C}_{0 \mathrm{~h}} \pm \mathrm{SD}, \mathrm{ng} / \mathrm{ml}$ & $3,666 \pm 1,168$ & $4,638 \pm 2,259$ & $1.09(0.88-1.35)$ \\
\hline Mean $\mathrm{C}_{\min } \pm \mathrm{SD}, \mathrm{ng} / \mathrm{ml}$ & $2,160 \pm 835$ & $3,331 \pm 1,554$ & $1.44(1.13-1.82)$ \\
\hline Mean $\mathrm{C}_{\max } \pm \mathrm{SD}, \mathrm{ng} / \mathrm{ml}$ & $5,768 \pm 1,374$ & $6,831 \pm 1,999$ & $1.11(0.98-1.26)$ \\
\hline Mean $\mathrm{AUC}_{12 \mathrm{~h}} \pm \mathrm{SD}, \mathrm{ng} \cdot \mathrm{h} / \mathrm{ml}$ & $45,698 \pm 13,727$ & $60,831 \pm 22,060$ & $1.24(1.09-1.42)$ \\
\hline Median $t_{\max }($ range $), h$ & $3.0(2.0-5.0)$ & $4.0(0-6.0)$ & - \\
\hline
\end{tabular}

${ }^{*} \mathrm{n}=10$ for $\mathrm{C}_{\min }, \mathrm{C}_{\max }, \mathrm{AUC}_{12 \mathrm{~h}}$ and $\mathrm{t}_{\max } . \mathrm{SD}=$ Standard deviation; $\mathrm{t}_{\max }=$ time to maximum plasma concentration; DRV/r = darunavir with low-dose ritonavir; IDV = indinavir; LS = least-squares; CI = confidence interval; $\mathrm{n}=$ number of volunteers; $\mathrm{C}_{0 \mathrm{~h}}=$ predose plasma concentration; $\mathrm{C}_{\mathrm{min}}=$ minimum plasma concentration; $\mathrm{C}_{\max }=$ maximum plasma concentration; $\mathrm{AUC}=$ area under plasma concentration time curve.

Table 2. Pharmacokinetic results of indinavir on day 7 after administration of IDV/r 800/100 mg b.i.d. alone (treatment B) and in combination with DRV $400 \mathrm{mg}$ b.i.d. (treatment C)

\begin{tabular}{|c|c|c|c|}
\hline Pharmacokinetic parameter & $\begin{array}{l}\text { IDV/r alone } \\
\text { (treatment B; reference) }\end{array}$ & $\begin{array}{l}\mathrm{IDV} / \mathrm{r}+\mathrm{DRV} \\
\text { (treatment C; test) }\end{array}$ & $\begin{array}{l}\text { LS means ratio test/ } \\
\text { reference }(90 \% \mathrm{CI})\end{array}$ \\
\hline $\mathrm{n}$ & $10^{*}$ & 10 & 9 \\
\hline Mean $\mathrm{C}_{0 \mathrm{~h}} \pm \mathrm{SD}, \mathrm{ng} / \mathrm{ml}$ & $2,305 \pm 1,175$ & $3,950 \pm 1,976$ & $1.55(1.12-2.15)$ \\
\hline Mean $\mathrm{C}_{\min } \pm \mathrm{SD}, \mathrm{ng} / \mathrm{ml}$ & $1,134 \pm 589$ & $2,750 \pm 1,257$ & $2.25(1.63-3.10)$ \\
\hline Mean $\mathrm{C}_{\max } \pm \mathrm{SD}, \mathrm{ng} / \mathrm{ml}$ & $12,687 \pm 1,980$ & $14,100 \pm 2,688$ & $1.08(0.95-1.22)$ \\
\hline Mean $\mathrm{AUC}_{12 \mathrm{~h}} \pm \mathrm{SD}, \mathrm{ng} \cdot \mathrm{h} / \mathrm{ml}$ & $73,058 \pm 15,896$ & $94,550 \pm 23,129$ & $1.23(1.06-1.42)$ \\
\hline Median $\mathrm{t}_{\max }($ range $), \mathrm{h}$ & $3.0(2.0-5.0)$ & $3.0(2.0-5.0)$ & - \\
\hline
\end{tabular}

* $\mathrm{n}=9$ for $\mathrm{C}_{\min }, \mathrm{C}_{\max }, \mathrm{AUC}_{12 \mathrm{~h}}$ and $\mathrm{t}_{\max } . \mathrm{SD}=$ Standard deviation; $\mathrm{t}_{\max }=$ time to maximum plasma concentration; IDV/r = indinavir with low-dose ritonavir; DRV = darunavir; LS = least-squares; CI = confidence interval; $\mathrm{n}=$ number of volunteers; $\mathrm{C}_{0 \mathrm{~h}}=$ predose plasma concentration; $\mathrm{C}_{\min }=$ minimum plasma concentration; $\mathrm{C}_{\max }=$ maximum plasma concentration; $\mathrm{AUC}=$ area under plasma concentration time curve.

presence of DRV: the $\mathrm{AUC}_{12 \mathrm{~h}}, \mathrm{C}_{\min }$ and $\mathrm{C}_{\max }$ of IDV were increased by 23,125 and $8 \%$, respectively, compared with treatment with IDV/r alone.

The mean plasma concentration-time curves of RTV showed that at steady-state the plasma concentrations of RTV were comparable during the treatments with IDV/r (treatment B) and DRV/r with IDV (treatment C), and that the plasma concentrations of RTV during these two treatments with IDV were higher compared with those obtained during treatment with DRV/r alone (treatment A). The LS means ratios of treatment $\mathrm{C}$ versus treatment $\mathrm{B}$, showed relatively small increases of 12,24 and $9 \%$ for, respectively, $\mathrm{AUC}_{12 \mathrm{~h}}, \mathrm{C}_{\min }$ and $\mathrm{C}_{\max }$ of $\mathrm{RTV}$, reflecting the comparable plasma concentrations of RTV during both treatments with IDV. However, LS means ratios of treatment $\mathrm{C}$ versus treatment $\mathrm{A}$, showed increases of 166 , 183 and $108 \%$ for, respectively, $\mathrm{AUC}_{12 \mathrm{~h}}, \mathrm{C}_{\min }$ and $\mathrm{C}_{\max }$ of RTV. Thus, PK parameters of RTV were 2- to 3 -fold higher in the presence of IDV compared with treatment with $\mathrm{DRV} / \mathrm{r}$ alone.

Individual predose plasma concentrations of DRV, IDV and RTV for the morning intakes of these drugs on days 5, 6 and 7 showed that steady-state conditions were achieved (i.e. drug concentrations had plateaued and were comparable between these 3 days) for all drugs prior to full pharmacokinetic blood sampling days (day 7). In 
addition, plasma concentrations of DRV, IDV and RTV in predose samples of day 1 of all treatments were below the LLOQ, indicating that the wash-out period of 7 days between consecutive treatments was sufficient.

\section{Safety and Tolerability}

There were no serious AEs reported during the study. All 17 volunteers reported at least one AE during the study; 67\% (8/12 volunteers) during treatment $A$ (DRV/r), $100 \%(12 / 12$ volunteers) during treatment B (IDV/r), and $100 \%$ (11/11 volunteers) during treatment C (DRV/r + IDV). The most commonly (in $>3$ volunteers) reported AEs were skin and subcutaneous tissue disorders ( $\mathrm{n}=15$; $88 \%)$, nervous system disorders (71\%), laboratory investigation-related AEs (59\%) and gastrointestinal disorders (53\%). The overall incidence of these AEs was higher during the treatments that included IDV (treatments B and C) compared with treatment with DRV/r alone (treatment A). Eight volunteers discontinued the study treatment during the first session for grade 2 maculopapular rash (per protocol, subjects had to discontinue due to grade 2 rash or greater): two during treatment $\mathrm{A}$, three during treatment $\mathrm{B}$, two during treatment $\mathrm{C}$, and one volunteer during the washout following treatment A. All AEs were grade 1 or 2 in severity, except for one grade 3 $\mathrm{AE}$ (increased blood bilirubin) during co-administration of DRV/r and IDV (treatment C).

Two grade 3 treatment-emergent laboratory abnormalities were reported: hypercholesterolemia with treatment $\mathrm{B}$ and hyperbilirubinemia with treatment $\mathrm{C}$. All other treatment-emergent laboratory abnormalities were grade 1 or 2 in severity. Elevated bilirubin levels were reported frequently during treatments with IDV.

No clinically relevant changes in vital signs or ECG parameters were noted during the study.

\section{Discussion}

A number of different strategies aimed at managing patients with HIV infection who have experienced treatment failure have been explored in clinical practice, including administration of two PIs in combination with low-dose RTV as a pharmacokinetic booster. Although the combination of two PIs could theoretically extend the spectrum of activity against HIV and increase the potency of the regimen, in-vitro studies have shown antagonistic effects (as well as synergistic and additive effects) with different PI combinations [14] and current treatment guidelines do not recommend double-boosted PI combinations [7]. Specifically, the long-term safety and efficacy of DRV/r combined with IDV have not been evaluated in HIV-infected patients.

The pharmacokinetics of a range of double-boosted PI regimens have been investigated in both healthy volunteers and HIV-1-infected patients $[15,16]$. As PIs are metabolized by CYP450 enzymes (predominantly CYP3A4) and may either induce or inhibit CYP3A4, clinically relevant drug-drug interactions can occur when they are combined. Tipranavir, for example, has been shown to reduce plasma concentrations of saquinavir, lopinavir (LPV) and amprenavir, although the clinical relevance of this is unknown [16]. Similarly, use of fosamprenavir/ $\mathrm{LPV} / \mathrm{r}$ regimens is characterized by a complex drug-drug interaction between amprenavir and LPV/r [17]. In contrast, results showing a lack of any significant interaction have been reported in patients treated with saquinavir/ LPV/r combinations $[18,19]$. Atazanavir in combination with saquinavir and low-dose RTV has shown a favorable pharmacokinetic interaction [20,21]. However, LPV and saquinavir reduced the AUC and $\mathrm{C}_{\min }$ of DRV and therefore it is not recommended to combine LPV or saquinavir with DRV/r $[1,2]$.

In the present study, coadministration of IDV, DRV and low-dose RTV resulted in an increased steady-state systemic exposure of IDV compared with administration without DRV. Based on the LS means ratios, the $\mathrm{AUC}_{12 \mathrm{~h}}$ of IDV was increased by $23 \%, \mathrm{C}_{\min }$ by $125 \%$ and $\mathrm{C}_{\max }$ by $8 \%$. The increase in exposure to IDV presumably occurs via DRV inhibition of CYP3A4-mediated metabolism of IDV [22] or possibly by inhibition of the drug transporter P-glycoprotein or other transporters in the intestine and or the liver [23]. The presence of IDV also increased the pharmacokinetic parameters of DRV: the LS means ratios of DRV $\mathrm{AUC}_{12 \mathrm{~h}}, \mathrm{C}_{\min }$ and $\mathrm{C}_{\max }$ were increased by 24,44 and $11 \%$, respectively, compared with administration of DRV/r alone. The inhibition of CYP3A4 or P-glycoprotein or other drug transporters by IDV [22, 23] likely explains the increase in DRV exposure. Systemic exposure of RTV was comparable during both treatments with IDV (treatments B and C), irrespective of the presence of DRV; however, pharmacokinetic parameters of RTV were higher (approximately 2 - to 3 -fold) in the presence of IDV compared to treatment with DRV/r alone (treatment A).

No serious AEs were reported. In general, AEs and laboratory abnormalities were more commonly reported during treatments including IDV. In this trial performed in healthy volunteers, skin and subcutaneous tissue disorders were reported frequently across all treatment 
groups. A total of eight volunteers, two to three per treatment; had to discontinue the study due to grade 2 maculopapular rash, as per protocol. Treatments including IDV were also associated with (asymptomatic) elevations in bilirubin levels, which is a known side effect of IDV therapy [5]. When used in combination with DRV/r, dose adjustment of IDV to $600 \mathrm{mg}$ b.i.d. may be warranted in cases of intolerance.

Given the declining use of IDV in clinical practice, it is unlikely that the combination of DRV/r and IDV will be a common treatment option for HIV-1-infected patients. Although the use of IDV boosted with RTV (800/100 mg b.i.d.) removed the food restriction, reduced the pill burden and enabled a more convenient twice-daily dosing schedule, the regimen was often poorly tolerated, and its use diminished as newer, better tolerated PIs, such as LPV and atazanavir, became available [24]. Nonetheless, in the small number of patients who remain on IDV regimens, and in those with limited treatment options, it may become desirable to administer combination therapy with DRV/r, hence information on their compatibility is clinically relevant.
This interaction study has been performed with a lower DRV/r dose (400/100 mg b.i.d.) than the recommended dosage for treatment-experienced adults (i.e., $600 / 100 \mathrm{mg}$ b.i.d.). At the time of conduct of this study, dose-finding studies were ongoing with treatment-experienced adult patients (with DRV/r 400/100 mg q.d., 800/100 mg q.d., $400 / 100 \mathrm{mg}$ b.i.d. and $600 / 100 \mathrm{mg}$ b.i.d.). A similar effect of DRV/r on IDV exposure is expected with the currently approved 600/100 $\mathrm{mg}$ b.i.d. dose of DRV/r as observed in this study with DRV/r 400/100 mg b.i.d., based on the lack of dose-proportionality in DRV pharmacokinetics between DRV/r 400/100 and 600/100 mg b.i.d. [25].

In conclusion, DRV/r may be co-administered with IDV and a dose adjustment of IDV from $800 \mathrm{mg}$ b.i.d. to $600 \mathrm{mg}$ b.i.d. may be warranted in cases of intolerance.

\section{Acknowledgements}

This study was financially supported by Tibotec Pharmaceuticals Ltd. The authors thank Iris Weimar and Catherine M. Bragg of Gardiner-Caldwell Communications for medical writing support.

\section{References}

1 PREZISTA $^{\mathrm{TM}}$ (darunavir) Summary of Product Characteristics, 2009, Tibotec Inc. http:// www.emea.europa.eu/humandocs/PDFs/ EPAR/prezista/emea-combined-h707en.pdf (accessed 19 November 2009).

2 PREZISTA $^{\mathrm{TM}}$ (darunavir) US Prescribing Information; revised June 2009. Tibotec Inc. http://www.prezista.com/prezista/documents/us_package_insert.pdf. (accessed 19 November 2009)

-3 De Meyer S, Azijn H, Surleraux D, et al: TMC114, a novel human immunodeficiency virus type 1 protease inhibitor active against protease inhibitor-resistant viruses, including a broad range of clinical isolates. Antimicrob Agents Chemother 2005;49:2314-2321.

4 Sekar V, Guzman S, Stevens T, et al: Absolute bioavailability of TMC114 administered in the absence and presence of low-dose ritonavir. 7th International Workshop on Clinical Pharmacology of HIV Therapy, Lisbon, 2006, abstr 86

5 Crixivan ${ }^{\circledR}$ (indinavir) Summary of Product Characteristics, revised 7 October 2006. Merck Sharp \& Dohme Ltd. http://www. emea.europa.eu/humandocs/PDFs/EPAR/ Crixivan/H-128-PI-en.pdf (accessed 29 April 2008).
-6 Saah AJ, Winchell GA, Nessly ML, et al: Pharmacokinetic profile and tolerability of indinavir-ritonavir combinations in healthy volunteers. Antimicrob Agents Chemother 2001;45:2710-2715.

7 Panel on Antiretroviral Guidelines for Adults and Adolescents: Guidelines for the use of antiretroviral agents in HIV-1-infected adults and adolescents. Department of Health and Human Services, 2008, pp 1-139. http://www.aidsinfo.nih.gov/ContentFiles/ AdultandAdolescentGL.pdf (accessed 19 November 2009).

8 Boffito M, Moyle GJ: Pharmacokinetic considerations for combining 2 protease inhibitors. AIDS Read 2004;14:110-112, 115-116.

9 Norvir $^{\circledR}$ (ritonavir) Summary of Product Characteristics; revised 27 August 2006, Abbott Laboratories L., UK. http://www.emea. europa.eu/humandocs/PDFs/EPAR/Norvir/H-127-PI-en.pdf (accessed 29 April 2008).

10 Sekar V, Spinosa-Guzman S, Meyvisch P, et al: Cocktail study to investigate the in-vivo drug interaction potential of darunavir coadministered with low-dose ritonavir (DRV/ r; RTV) on cytochrome P450 enzymes 2D6, 2C9 and 2C19. 9th International Workshop on Clinical Pharmacology of HIV Therapy (IWCPHIV), New Orleans, 2008, abstr P23.
11 Bouche MP, Michielsen L, Piot M, et al: Swift and simultaneous determination of darunavir (TMC114) and ritonavir in human plasma using LC-MS/MS. 17th Int Mass Spectrom Conf (IMSC), Prague, 2006, abstr TuP-042.

12 Data on File. Tibotec Inc.

13 Koch G: The use of nonparametric methods in the statistical analysis of the two-period change-over design. Biometrics 1972;28: 577-584.

14 Bulgheroni E, Citterio P, Croce F, et al: Analysis of protease inhibitor combinations in vitro: activity of lopinavir, amprenavir and tipranavir against HIV type 1 wild-type and drug-resistant isolates. J Antimicrob Chemother 2004;53:464-468.

15 Boffito M, Maitland D, Samarasinghe Y, et al: The pharmacokinetics of HIV protease inhibitor combinations. Curr Opin Infect Disease 2005; 18:1-7.

16 Walmsley S, Leith J, Katlama C, et al: Pharmacokinetics and safety of tipranavir/ritonavir (TPV/r) alone or in combination with saquinavir (SQV), amprenavir (APV), or lopinavir (LPV): interim analysis of BI1182.51. 15th International AIDS Conference, Bangkok, 2004, abstr WeOrB1236. 
-17 Kashuba AD, Tierney C, Downey GF, et al: Combining fosamprenavir with lopinavir/ ritonavir substantially reduces amprenavir and lopinavir exposure: ACTG protocol A5143 results. AIDS 2005;19:145-152.

$\checkmark 18$ Stephan C, Hentig N, Kourbeti I, et al: Saquinavir drug exposure is not impaired by the boosted double protease inhibitor combination of lopinavir/ritonavir. AIDS 2004; 18:503-508.

19 Ribera E, Lopez RM, Diaz M, et al: Steadystate pharmacokinetics of a double-boosting regimen of saquinavir soft gel plus lopinavir plus minidose ritonavir in human immunodeficiency virus-infected adults. Antimicrob Agents Chemother 2004;48:4256-4262.
20 Boffito M, Maitland D, Dickinson L, et al: Pharmacokinetics of saquinavir hard gel (SQV)/ritonavir and atazanavir when combined once daily in HIV type 1-infected individuals administered different atazanavir doses. AIDS Res Hum Retrovir 2006;22:749756.

21 Boffito M, Kurowski M, Kruse G, et al: Atazanavir enhances saquinavir hard-gel concentrations in a ritonavir-boosted once-daily regimen. AIDS 2004;18:1291-1297.

22 Chiba M, Hensleigh M, Nishime JA, Balani SK, Lin JH: Role of cytochrome P450 3A4 in human metabolism of MK-639, a potent human immunodeficiency virus protease inhibitor. Drug Metab Dispos 1996;24:307314.
23 Profit L, Eagling V, Back D: Modulation of P-glycoprotein function in human lymphocytes and Caco-2 cell monolayers by HIV-1 protease inhibitors. AIDS 1999;13:16231627.

24 Jiménez-Nácher I, García B, Barreiro P, et al: Trends in the prescription of antiretroviral drugs and impact on plasma HIV-RNA measurements. J Antimicrob Chemother 2008; 62:816-22.

25 Sekar V, de Meyer S, Vangeneugden T, et al: Pharmacokinetic/ pharmacodynamic (PK/ PD) analyses of TMC114 in the POWER 1 and POWER 2 trials in treatment-experienced HIV-infected patients. Conference on Retroviruses and Opportunistic Infections (CROI), Denver, 2006, abstr J-121. 